\title{
Adaptação da capoeira para idosas reumáticas
}

\author{
Capoeira adaptation for elderly rheumatics
}

DOI: $\underline{\text { http://dx.doi.org/10.36453/2318-5104.2018.v16.n1.p47 }}$

\author{
Jefferson Santos Silva ${ }^{1}$, Silvana dos Santos ${ }^{2}$ \\ ${ }^{1}$ União das Faculdades Metropolitana de Maringá (Unifamma) \\ ${ }^{2}$ Universidade Estadual de Maringá (UEM)
}

\begin{abstract}
RESUMO
Este estudo teve como objetivo sistematizar a prática da capoeira para idosos. Participaram do estudo vinte idosas reumáticas, com faixa etária entre 65 a 82 anos da Associação Maringaense dos Reumáticos (AMAR) da cidade de Maringá (Pr.). Contou-se com 12 encontros de sessenta minutos duas vezes semanais. As participantes do estudo nunca haviam praticado a capoeira ou nada similar a modalidade. No entanto, todas eram participantes de um programa de atividade física ofertado para terceira idade. Foi realizada uma sistematização de ensino da capoeira, iniciando com a história da modalidade e iniciação a musicalização. Em relação aos movimentos, partiu-se de uma sequência que atendessem os movimentos corporais numa progressão do mais simples para os mais complexos. Os encontros foram fotografados e filmados. Estes recursos posteriormente foi suporte para a análise dos dados, também foi elaborado um diário de campo para registro das especificidades ocorridas em cada encontro, como evolução de movimentos e melhorias das habilidades motoras, sociabilização entre participantes, cooperação para a realização conjunta de movimentos considerados complexos, memorização de cantos, entre outras competências. A análise dos dados foi realizada mediante os pressupostos teórico-metodológicos da análise de conteúdo de Bardin. Os resultados obtidos no decorrer das vivências corporais com a prática da capoeira promoveram autoconhecimento corporal, identificando as possibilidades e limitações corporais, promoveu melhoras significativas no condicionamento físico das idosas, ampliando benefícios nos aspectos sócio afetivos, cognitivo, nas habilidades motoras e ampliação do processo sociabilizador dos sujeitos.
\end{abstract}

PALAVRAS-CHAVE: Idosas; Capoeira; Atividade física.

\section{ABSTRACT}

This study aimed to systematize the practice of capoeira for the elderly. Twenty elderly women aged between 65 and 82 years of age participated in the study of the Maringaense de Rheumáticos Association (AMAR) in the city of Maringá (Paraná - Brasil). Twelve meetings of sixty minutes twice weekly were counted. The study participants had never practiced capoeira or anything equal to the modality. However, they were all participants in a physical activity program offered for the elderly. A systematization of teaching of capoeira was carried out, starting with the history of the modality and initiation to musicalization. In relation to the movements, we started with a sequence that served the body movements in a progression from the simplest to the most complex. The meetings were photographed and filmed. These resources were subsequently used to support the analysis of the data. A field diary was also written to record the specificities of each encounter, such as the evolution of movements and improvements in motor skills, socialization among participants, cooperation for joint movements of complex movements, memorization of songs, among other skills. Data analysis was performed using the theoretical-methodological assumptions of the Bardin content analysis. The results obtained during the corporal experiences with the practice of capoeira promoted self-knowledge of the body, identifying the possibilities and limitations of the body, promoted significant improvements in the physical conditioning of the elderly, increasing benefits in the socio-affective, cognitive aspects, motor skills and process enlargement sociabilizer of the subjects.

KEYWORDS: Elderly; Capoeira; Physical activity. 


\title{
INTRODUÇÃO
}

Este estudo evidenciou possibilidades de aplicabilidade da capoeira em sua ramificação contemporânea dos diferentes âmbitos de atuação/intervenção, dando destaque a população idosa. Franchi e Junior (2005) estabelecem como idosa toda pessoa que atinge 60 anos ou mais. A opção pela população em questão se deu por entendermos a capoeira enquanto prática propiciadora de valorização, autoafirmação, socialização, melhoria da qualidade de vida, bem como propulsora de atividades culturais.

O idoso ao atingir essa fase, tende a minimizar algumas habilidades corporais, tais como, perda de densidade óssea, equilíbrio, flexibilidade, agilidade, perda de massa magra, refinamento da pele em função da diminuição de colágeno e elastina, morte celular do fígado e rins, ocorrência de problemas posturais dando aparência de estatura encolhida, hipercifose torácica e alteração dos arcos dos pés, com o envelhecimento vem também à demência que é um déficit progressivo da cognição que afeta a memória (COELHO et al., 2013).

No entanto, há formas de retardar os danos causados no processo natural do envelhecimento. Tanto a promoção do envelhecimento ativo populacional, quanto o estímulo a cognição e a prática de atividade física (hidroginástica, esportes adaptados, alongamentos, entre outros) são meios favoráveis que contribuem para a promoção da saúde e bem-estar.

De acordo com a definição atribuída pelo Ministério da Saúde (2010), entende-se que,

\begin{abstract}
A promoção da saúde é uma estratégia de articulação transversal na qual se confere visibilidade aos fatores que colocam a saúde da população em risco e às diferenças entre necessidades, territórios e culturas presentes no nosso país, visando à criação de mecanismos que reduzem as situações de vulnerabilidade, defendem radicalmente a equidade e incorporem a participação e o controle sociais na gestão das políticas públicas (p. 12).
\end{abstract}

Assim, tomamos como objetivo neste recorte, sistematizar o ensino da capoeira para idosos. Visto que, Santos $(2002$, p.17) considera que a associação da capoeira como promoção da saúde,

Está relacionada com o bem-estar da saúde física, mental e espiritual que a capoeira exerce em seus protagonistas, assim como o bem-estar da coletividade e da nação, por diminuir as enfermidades das pessoas que passam a serem adeptas de sua manifestação.

Nessa mesma linha de raciocínio, Veronese e Moré (2009) pontuam que a capoeira é um instrumento grandioso e terapêutico, que contribui para/no tratamento de pessoas com transtornos psíquicos por envolver o jogo, musicalidade, movimentos corporais e trabalhos viso-motores ao estimular a utilização do olhar (esquivar dos golpes). A defesa dos autores se dá principalmente pela crença da conscientização corporal advinda do diálogo corporal através de movimentos lúdicos e ao mesmo tempo precisos, bem como a ampliação da socialização entre praticantes.

Todavia, a ausência de uma pedagogia de ensino da capoeira para idosos, a qual motivou este estudo, não se explica isoladamente pela falta de sistematizações ou trabalhos acadêmicos. É também uma limitação advinda dos planos estrutural, político e econômico. No entanto, não se pode negar que a partir de intervenções advindas do plano da cultura se possa estabelecer relação entre os diferentes sujeitos, dando sentido/significado às ações.

Se partirmos do pressuposto da utilização da capoeira em suas diferentes ramificações, então, iremos ao encontro do que Portela e Jesus (2011), defendem, pois, a capoeira não é só um esporte, ela envolve atrativos que estão envolvidos na raiz do povo brasileiro, com isso, há a ocorrência da disseminação de diferentes expressões culturais advindas pela prática da capoeira.

Tal diversidade faz com que diferentes pessoas se tornem praticantes da capoeira, Lussac (2010) pondera que a capoeira pode ser praticada por diferentes faixas etárias, desde crianças até idosos, e que sua busca se relaciona a diversos fatores, tais como: ritmo, a beleza dos movimentos, e até mesmo a estética.

A multiplicidade de interesses pela prática pode ser associada aos apontamentos de Reis (2001) ao afirmar que a capoeira possui riquezas naturais de movimentos que envolvem esforços que vai do máximo até o submáximo, além de deixar o praticante condicionado fisicamente. Todavia, pouco se encontra na literatura 
acerca de estudos da biomecânica dos movimentos da capoeira.

Neste aspecto, Brennecke, Amadio, Serrão (2005) sugerem que uma boa sequência de movimentos se inicia com a meia lua de frente, martelo, negativa, evitando o parafuso e a armada, pois, esses últimos exigem maior desenvoltura do praticante. Desse modo, apropriar-se de uma sequência básica de movimentos permite que a capoeira seja executada enquanto atividade física, pois, nesta conjuntura os movimentos podem ser realizados em um primeiro momento sequenciados sem ater-se primordialmente a técnica de execução, mas, identificando as limitações do executante, bem como o reconhecimento das possibilidades corporais, uma vez que a atividade física favorece o aprimoramento da consciência corporal.

\section{MÉTODOS}

Este estudo é um recorte do trabalho de conclusão de curso em Educação Física Bacharelado da União das Faculdades Metropolitana de Maringá, com aprovação no Comitê de Ética 5539 - sob parecer de aceite no 1694593. O estudo foi composto por 20 (vinte) idosas reumáticas da Associação Maringaense de Apoio ao Reumático na cidade de Maringá ( $\mathrm{Pr}$ ), com idade oscilando entre 60 a 85 anos, estando $40 \%$ na faixa etária de 71 a 77 anos, 30\% apresentando a faixa etária entre 66 a 70 anos, 20\% com idade entre 60 a 65 anos e 10\% das participantes com idade superior a 83 anos.

As participantes do estudo nunca haviam praticado a capoeira ou nada similar a modalidade. No entanto, todas eram participantes de um programa de atividade física ofertado para terceira idade, realizando aulas de alongamento duas vezes na semana, com duração de 40 minutos cada encontro.

A proposta da capoeira para esse grupo de idosas foi estabelecido por dois encontros semanais, com duração de uma hora, totalizando duas horas semanais adicionais às suas atividades cotidiana. Foi realizada uma sistematização de ensino da capoeira, iniciando com a história da modalidade e iniciação a musicalização. Em relação aos movimentos, partiu-se de uma sequência que atendessem os movimentos corporais numa progressão do mais simples para os mais complexos.

Os encontros foram fotografados e filmados. Estes recursos posteriormente foi suporte para a análise dos dados, bem como na promoção da ilustração do material inicial (Monografia apresentada a IES). Também foi elaborado pelos pesquisadores, um diário de campo para registro das especificidades ocorridas em cada encontro, como evolução de movimentos e melhorias das habilidades motoras, sociabilização entre participantes, cooperação para a realização conjunta de movimentos considerados complexos, memorização de cantos, entre outras competências.

Os resultados obtidos no decorrer das vivências corporais com a prática da capoeira foram anotados em diário de campo. Após três meses da prática da capoeira sistematizada para idosos com dois encontros semanais e duração de uma hora, foi realizada entrevista com as participantes utilizando as mesmas questões do questionário inicial, fazendo um comparativo dos dados levantados.

A análise dos dados foi realizada mediante os pressupostos teórico-metodológicos da análise de conteúdo de Bardin (1977), buscando a compreensão total das comunicações, fazendo uso do que o autor consagra como duas grandes funções: a) explorar o conteúdo e descobrir novos elementos; b) aparecimento das hipóteses que servem como diretrizes para o encaminhamento da pesquisa.

Os resultados foram apresentados a partir da análise e interpretação do discurso das participantes, das observações da forma como foram executados os movimentos propostos na sistematização de ensino da capoeira, bem como imagens (fotos e vídeos) obtidas no decorrer das aulas. Assim, Duarte (2002) pondera que fragmentos do discurso, imagens, trechos de entrevistas, expressões recorrentes e significativas, registros de práticas e de indicadores de sistemas classificatórios constituem traços, elementos em torno dos quais serão construídas as hipóteses e reflexões, levantadas as dúvidas ou reafirmadas às convicções

\section{RESULTADOS E DISCUSSÃO}

O contato inicial com a população em questão, já nos possibilitou as primeiras anotações em diário de campo, das quais notificamos dificuldade no andar, desestabilidade corporal (equilíbrio), perda de agilidade 
e flexibilidade. Ao verificar essas dificuldades iniciais já íamos traçando em nosso diário de campo estratégias que pudessem atender esse grupo com possíveis adaptações nos movimentos básico da capoeira, visto que, todas as idosas participantes do estudo apresentavam diagnóstico clínico reumático.

Para além dos movimentos corporais e suas fragilidades, identificamos também em algumas idosas a dificuldade em memorizar o refrão das músicas de capoeira (que adaptamos ao contexto das idosas). No que se referem as dificuldades citadas, autores como Galdino (2005) e Barbanti (2003) demonstraram em seus estudos que exercícios físicos atuam na melhoria da saúde física e psíquica de idosos. Estes estudos reforçam ainda, que o exercício físico diminui a ansiedade e depressão, atuando na prevenção de lesões.

Vale destacar que todas as participantes já possuíam hábitos direcionados às práticas de exercícios e atividades físicas, ainda assim, em alguns casos notou-se a necessidade de abordagens diferenciadas, tanto nos aspectos funcionais (habilidades motoras) quanto no estado emocional. Nos aspectos funcionais em virtude de algumas limitações no movimento, no estado emocional por apresentarem quadro de depressão leve.

Todavia, essas limitações não as faziam ficar de fora da proposta, ao contrário, tentavam superar as barreiras do que consideravam ser algo complexo. Talvez, as tentativas em realizar todas as atividades e exercícios propostos se deram ao fato de possuírem conscientização das melhorias recorrentes da atividade física. Neste aspecto, Boutcher (1993) apud Okuma (2009) pondera que,

As pessoas sentem-se bem consigo mesmas após a atividade física, o que pode ser devido a numerosos fatores, como melhora da imagem corporal resultante da perda de peso ou aumento da massa muscular. Bouchet faz ainda referência à autovalorização aumentada, decorrente da experiência de domínio, sentida através da realização por completar um esforço anteriormente pensado como impossível ou por ocorrer pela primeira vez (p. 87).

Todavia, a atividade física quando realizada constantemente além das melhorias em nível fisiológico e biológico, também contribui nos aspectos secundários, a exemplo da ocupação do tempo livre, criação de algumas obrigações a serem realizadas ao longo do dia, e integração em grupo. Okuma (2009) ressalta que as atividades grupais possibilitam ao idoso a satisfação pessoal, como também suporte social.

Pautado nos dizeres do autor supracitado, as participantes demonstraram gostar do contato com as demais e a socialização que os encontros promoviam, conforme anunciado por uma das participantes, "eu gosto bastante de vir para as aulas, me encontrar com minhas colegas, a gente se diverte e a atividade também faz bem para o nosso corpo" (Participante 5, 2017).

Além da socialização foi perceptível a compreensão da importância da realização de atividade física, conforme anunciado em um dos relatos,

Eu achava que nunca ia conseguir dançar a capoeira, tem essas cambalhotas que a gente vê, e ai pensei meu Deus, eu não vou conseguir rodar alto não, mas, depois entendi que não precisava fazer essas cambalhotas, que o importante mesmo era mexer o corpo para melhorar nossa saúde (Participante 7, 2017).

De acordo com Okuma (2009) as atividades ofertadas em grupo, proporcionam aos idosos, satisfação pessoal, suporte social, ao fato de constituir-se na presença do outro e dos recursos materiais fornecidos por parentes e amigos. $\mathrm{O}$ autor estabelece ainda, que as atividades em grupo reduzem o estresse, auxiliando o idoso a manter um autoconceito positivo ante a minimização de energia e as dificuldades que surgem.

Além disso, o suporte social associado à capacidade de execução de uma atividade contribui para reforçar a valorização pessoal, reforçando o sentimento de auto eficiência. Assim, pode-se atribuir que a prática da capoeira nesta faixa etária foi compreendida como uma atividade física que transcendeu a execução do "exercício", podendo ser considerada também enquanto prática de relacionamento social e identificação com pessoas com as mesmas características, estabelecendo um grupo propiciador de novas amizades.

Menino, quando eu falei na minha casa pros meus netos que eu ia começar fazer capoeira eles deram risada, e falaram vó, tá maluca, a senhora vai se machucar. Eu tive um pouco de receio sabe, mas agora eu ensino o meu neto na minha casa e ele me ajuda a gingar e fazer aqueles movimentos de levantar as pernas sabe, e todo mundo lá em casa está achando que eu já melhorei bastante (Participante 1 , 20017). 
Por outro lado, a capoeira enquanto elemento essencial deste estudo não deve ser considerada a "salvadora do mundo", mas, uma possibilidade acertada favorável à qualidade de vida do idoso de forma harmônica, capaz de gerar sensações a exemplo da alegria, bem estar e socialização entre os participantes, adjetivos estes, anunciado pelas participantes do estudo.

A partir das respostas obtidas nas entrevistas, criamos um quadro analítico do qual foram extraídas as principais temáticas ressaltadas pelas idosas, facilitando uma visão geral de todos os assuntos abordados no questionário. Sendo situadas as categorias encontradas como medidas de auxiliar na eleição das subcategorias.

Nesse sentido, o quadro a seguir contém termos transcritos das respostas obtidas e que chamaram a atenção, por atenderem aos objetivos do estudo e por que foram enfatizados na linha de raciocínio dos sujeitos participantes dessa pesquisa.

Quadro 1. Temas associados à prática da capoeira por idosos pós-questionário.

\begin{tabular}{|ll|}
\hline Sujeito & Variáveis \\
\hline Idosa 1 & Ressaltou a alegria que a capoeira passa \\
\hline Idosa 2 & É bom para agilidade \\
\hline Idosa 3 & É bom porque é uma atividade que mexe com o corpo todo \\
\hline Idosa 4 & Levanta o astral; mexe com o corpo todo \\
\hline Idosa 5 & Traz alegria; A capoeira passa satisfação \\
\hline Idosa 6 & Mexem com o corpo todo \\
\hline Idosa 7 & Bom para memória \\
\hline Idosa 8 & Bom porque trabalha o corpo todo; consciência corporal \\
\hline Idosa 9 & É legal porque trabalha o corpo todo \\
\hline Idosa 10 & Gostei porque trabalha o equilíbrio \\
\hline Idosa 11 & $\begin{array}{l}\text { É bom para mente; comecei a amarrar o cadarço porque } \\
\text { não estava conseguindo mais; flexibilidade }\end{array}$ \\
\hline Idosa 12 & Gostei das músicas \\
\hline Idosa 13 & $\begin{array}{l}\text { É bom para a convivência com as pessoas; Quebrou precon- } \\
\text { ceito que tinha com a capoeira }\end{array}$ \\
\hline Idosa 14 & Gostei porque o professor é muito atencioso \\
\hline Idosa 15 & Bom para memória \\
\hline Idosa 16 & Bom porque o canto é bom para memória \\
\hline Idosa 17 & Diminuiu as dores que eu tinha nas pernas \\
\hline Idosa 18 & É legal porque é muito alegre \\
\hline Idosa 19 & O professor passa confiança e é alegre \\
\hline Idosa 20 & Para mim que gosto de dançar foi muito bom \\
\hline
\end{tabular}

Fonte: Resposta obtida dos questionários plicados pelos pesquisadores.

Esse procedimento analítico foi em parte influenciado pelos procedimentos hermenêuticos, na perspectiva que cada resposta carrega em si diferentes possibilidades de leitura. Portanto, as respostas obtidas no questionário não são transparentes, como uma versão fiel da realidade. As falas são carregadas de subjetividade, interesses, lapsos, silêncios, desejos e lembranças, algumas delas falsas.

A Figura 1 destacou as principais respostas, evidenciando as mais relevantes na tocante qualidade de vida, diferentes sensações, conscientização corporal. Após a construção do quadro foi possível identificar proximidades nas respostas abertas, sendo criadas quatro categorias abarcando a maior parte das definições atribuída pelas idosas. 


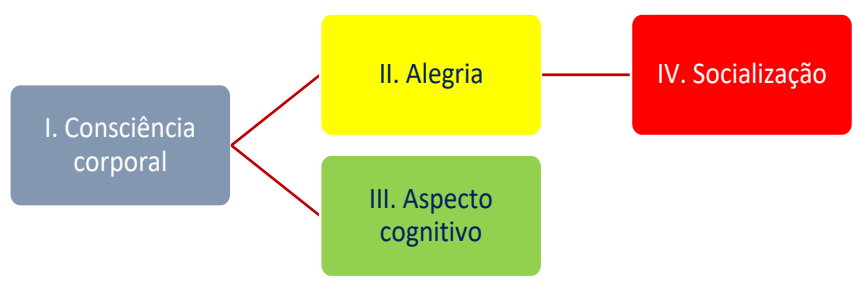

Figura 1. Organograma das categorias de análise do fenômeno situado.

Das categorias encontradas, podemos estabelecer que a compreensão de consciência corporal para a prática da capoeira com as idosas participantes da pesquisa, cinco delas apontaram que a prática da capoeira amplia a consciência corporal. Nos dizeres dessas senhoras, a modalidade "mexe com todo corpo".

Com esse discurso, podemos compreender que a percepção corporal permite identificar limitações e possibilidades de movimento. A esse respeito, Moreira apud Brandl (2002, p. 1) propõe que "há necessidade de compreender a prática da atividade física sobre o enfoque de que a Educação Física tem o papel de tratar o corpo não como objeto, e sim como sujeito da ação".

Todavia, dentre os diferentes aspectos que envolvem o envelhecimento, não se pode desconsiderar a existência da baixa relação corpo/expressão/mundo. Tal fato reduz a visão global das necessidades do corpo, de modo que não seja perceptível a conscientização sobre ele. Assim, para que ocorra a interação sujeito/ corpo é necessária a construção de uma relação aberta na qual se vivencie as diferentes experiências corporais. Cavalari (2005, p. 58), atribui que consciência corporal se relaciona com,

O reconhecimento do todo que é corpo (no sentido de corporeidade), assim como dos segmentos que o compõem: músculos, ossos, articulações, etc; é o conhecimento das possibilidades de movimento e da organização dos sistemas, do grau de tonicidade muscular, da postura, do funcionamento do organismo e de suas alterações, possibilitando conhecer as diversas origens das tensões, das dores, etc; é aprender a dosar a energia despendida num esforço, tendo ciência das limitações, seja numa tentativa de supera-las, ou até mesmo aprendendo a conviver com elas, descobrindo o prazer e o desprazer de viver, desenvolvendo a percepção das sensações (temperatura, volume, peso, comprimento). É o conhecimento de si.

Assim, a consciência corporal poderá ser desenvolvida por meio de estímulos que permitem as mais variadas possibilidades de movimentos, seja individualmente ou coletivamente. Autores como Medina (1987); Brandi (2002); Angheben (2005), entre outros, abordam que a consciência corporal quando reconhecida pelo individuo proporciona escolhas mais saudáveis de estilo de vida, o que gera uma prática prazerosa ao fato de respeitar as individualidades de cada sujeito.

No grupo realizado o estudo, a capoeira foi tornando-se uma prática corporal propulsora de prazer e autoconhecimento corporal a partir da exploração de movimentos simples com diferentes técnicas de aplicabilidade. Para melhor compreensão da aplicabilidade e adaptação do ensino da capoeira para idosos, o Quadro 2 apresenta a sistematização dos movimentos básicos.

A partir das adaptações sugeridas no quadro, as relações dialéticas que contemplam o "conjunto" corpo/ mundo puderam ser consideradas enquanto manifestações que transformam a corporeidade em expressões significativas da existência humana, sendo traduzidas pelas ações cotidianas que se atentam aos movimentos e a relação do corpo com o espaço que ele ocupa, despertando no indivíduo um olhar centrado no próprio corpo a ponto de ampliar a capacidade de movimento. Assim, a capoeira torna-se um forte elemento para conscientização corporal, em virtude de sua dinamicidade, de modo a familiarizar o idoso às possibilidades e limitações corporais, a partir de gestos associados à cadência rítmica, gestualidade, e dinâmicas em grupos.

No que tange a categoria alegria, quatro das participantes atribuíram que a prática da capoeira proporciona alegria, levanta o astral, promove satisfação. Essas definições podem ser consideradas ao fato da atividade física ser propulsora para a melhora do humor, aceitação do fenômeno envelhecimento e pelo proporcionamento de bem-estar (LUSSAC, 2004). 
Quadro 2. Sistematização de ensino dos movimentos básicos para terceira idade.

\begin{tabular}{|c|c|c|}
\hline Movimento & Execução & Adaptação \\
\hline Ginga & $\begin{array}{l}\text { Movimentação básica da capoeira, que dará ori- } \\
\text { gem a todos os demais movimentos. "A ginga } \\
\text { consiste no movimento ritmado de todo o corpo, } \\
\text { acompanhando o toque do berimbau, com a fi- } \\
\text { nalidade principal de manter o corpo relaxado e } \\
\text { o centro de gravidade do corpo em permanente } \\
\text { deslocamento, pronto para esquiva, ataque, con- } \\
\text { tra-ataque ou fuga. Durante o gingado, o pratican- } \\
\text { te deve manter-se em movimento permanente, } \\
\text { simulando tentativas de ataque e contra-ataque, } \\
\text { sempre atento às intenções do parceiro, em con- } \\
\text { tínua postura mental de esquiva e proteção dos } \\
\text { alvos potenciais de ataques" (MESTRE DECÂNNIO) }\end{array}$ & $\begin{array}{l}\text { Sugerir que o idoso (a) apoie-se numa cadeira a sua } \\
\text { frente. Apoiadas devem deslocar inicialmente somen- } \\
\text { te os membros inferiores alternadamente voltando } \\
\text { sempre na base paralela para realizar a troca de movi- } \\
\text { mentos inferiores. Após a vivência corporal com utili- } \\
\text { zação das cadeiras para realizar o movimento da ginga } \\
\text { separar o grupo em duplas para que realizem a ginga } \\
\text { segurando nas mãos da companheira de aula. }\end{array}$ \\
\hline Meia lua de frente & $\begin{array}{l}\text { É um golpe circular de ataque, realizado com a par- } \\
\text { te interna do pé. É aplicado em pé, de modo a lan- } \\
\text { çar a perna estendida à frente, saindo da paralela, } \\
\text { com movimento de abdução, sendo que fica uma } \\
\text { das pernas de base, sendo a parte interna do pé } \\
\text { que acerta o adversário. }\end{array}$ & $\begin{array}{l}\text { Foi dividida em duas fases sendo a primeira a execu- } \\
\text { ção da elevação do joelho com a perna flexionada na } \\
\text { altura que conseguisse realizar. A segunda fase exigia } \\
\text { manter uma das pernas elevadas para manutenção do } \\
\text { equilíbrio com a perna estendida, aumentando grada- } \\
\text { tivamente a complexidade dos movimentos até che- } \\
\text { gar na execução da meia lua de frente. }\end{array}$ \\
\hline Cocorinha & $\begin{array}{l}\text { Movimento de defesa, realizado na forma de cóco- } \\
\text { ras saindo da ginga, mantendo os pés na paralela e } \\
\text { uma das mãos sob defesa da face e a outra apoian- } \\
\text { do no chão atrás das costas. }\end{array}$ & $\begin{array}{l}\text { A adaptação consistiu em realizar o agachamento. } \\
\text { Esse movimento foi realizado em dois momentos:1. } \\
\text { Colocando cadeiras de alturas distintas (mais baixa e } \\
\text { normal) para que elas pudessem sentar aumentando a } \\
\text { complexidade do movimento de acordo com as capa- } \\
\text { cidades e limitações corporais das idosas. } 2 \text {. A medida } \\
\text { que o movimento ficou mais fácil tirou-se a cadeira } \\
\text { para que realizasse o agachamento sem apoio. }\end{array}$ \\
\hline Esquiva lateral & $\begin{array}{l}\text { É um golpe de defesa de ataques laterais, deve-se } \\
\text { flexionar a perna de apoio mantendo a perna livre } \\
\text { semi alongada com inclinação de tronco para a } \\
\text { lateral, a qual uma mão servirá de apoio no chão } \\
\text { para manutenção do equilíbrio corporal enquanto } \\
\text { a outra defende a face. }\end{array}$ & $\begin{array}{l}\text { Consistia em tentar relar os dedos da mão ou palma } \\
\text { da mão no chão. Em um primeiro momento utilizou-se } \\
\text { o apoio de uma cadeira ao lado de cada uma das ido- } \\
\text { sas para que tivesse segurança na realização do movi- } \\
\text { mento utilizando a cadeira como apoio, ao adquirir a } \\
\text { segurança substitui a cadeira por uma companheira, } \\
\text { realizando o movimento com a tentativa de tocar o } \\
\text { solo com os dedos ou a palma das mãos. }\end{array}$ \\
\hline Esquiva carioca & $\begin{array}{l}\text { Uma perna estendida para trás a outra flexionada } \\
\text { para frente em noventa graus, uma mão no chão e } \\
\text { a outra fazia defesa do rosto. }\end{array}$ & $\begin{array}{l}\text { Assim como a esquiva lateral o objetivo principal des- } \\
\text { sa esquiva também está em tocar o chão, porém com } \\
\text { descida frontal. Utilizou-se da sistematização da esqui- } \\
\text { va lateral inicialmente com apoio com a cadeira e após } \\
\text { com auxílio da companheira. }\end{array}$ \\
\hline
\end{tabular}

A cada encontro o diálogo e questionamentos acerca do que estavam sentindo tornou-se fluente e constante. Ações como estas, podem ser relacionadas ao comportamento, relacionamentos, emoções, sentimentos, atitudes, prazer e satisfação. Neste sentido, a capoeira enquanto manifestação cultural e artística possui elementos dos quais permitem que o praticante se sinta desinibido, sentindo-se mais "solto" ao mesmo tempo em que se amplia a expressividade dos indivíduos, além da melhoria e capacidade de experienciar novas oportunidades de movimentos corporais.

Pautado nos dizeres acima, vamos ao encontro com o discurso de Bechara (1985) afirmando que "a capoeira favorece o equilíbrio físico e psico afetivo daqueles que a praticam". Seguindo essa mesma lógica Lussac (1996, p. 37) corrobora dizendo que,

No campo afetivo, é importante a participação, a solidariedade e o respeito com as pessoas. Trabalha-se o lado emocional e comunicativo (inter e intrapessoal), através do extravasamento no canto e no gasto de energia contida dentro de nós, que soltamos quando dançamos e batucamos, lembramos da nossa história e cultura, louvamos Deuses e lembramos de personalidades e amigos. Através da música a alma se aflora no corpo, tornando-nos mais sensíveis e clareando nossa mente, dispersando os males, como o stress, a infidelidade, etc....; deixando-nos mais "leves", felizes e calmos após cada aula.

Pautado nos dizeres de Lussac (1996), pode-se evidenciar que as idosas praticantes da sistematização de ensino da capoeira, se inter-relacionaram de modo a ampliar os mais diferentes sentidos/significados 
atribuídos às diferentes formas de relacionamentos. O contato com o outro e a troca de experiências se fizeram de maneira a transcender a sensação de solidão maximizando o sentimento de alegria e bem-estar.

Para além da alegria que a capoeira oferece aos praticantes, é perceptível ainda a presença do espírito de colaboração entre o grupo. $\mathrm{O}$ apoio entre as idosas, mesmo que de forma verbal estimulava uma as outras à executarem os movimentos proporcionados dentro de suas limitações.

A cerca do papel da colaboração, Souza, Oliveira (2001, p. 45) atribui que,

A cooperação e participação social são despertadas na medida em que os alunos forem tomando ciência de que, na roda, todos são importantes. Para uma roda de capoeira ter um desenvolvimento satisfatório, todos precisam participar; apenas dois jogam de cada vez, mas são necessários os tocadores, os cantadores e os que batem palma e respondem ao coro. Este conjunto sincronizado e atuante é que faz a roda ter um bom desenvolvimento.

O apontamento de Souza, Oliveira (2001) fortalece o pressuposto de que a capoeira possui como foco, justificativas de ordem social, pois, o trabalho realizado pela modalidade sempre ocorrerá em grupo, principalmente no momento de execução da roda, pois, para a realização da mesma torna-se necessário a manutenção do ritmo através das palmas e da resposta ao coro, além dos tocadores e a participação simultânea de dois jogadores ao centro, ou seja, cada participante possui sua função e papel na roda.

Do mesmo modo, na capoeira direcionada para idosos prevaleceu princípios de colaboração e ampliação inter-relacional contribuindo para o bem-estar e aumento do sentimento de alegria grupal e individual.

Em relação aos aspectos cognitivos denominado nesse estudo, no decorrer das vivências corporais estimulou-se a memorização das músicas (re) criadas para a abordagem com o idoso. Entendemos que a abordagem com músicas nessa fase da vida, além de proporcionar prazer, estimula a utilização da memória no processo continuo de ensino/aprendizagem da capoeira.

Das participantes do projeto quatro delas atribuíram a importância da capoeira para/na melhoria de memória nessa fase. De acordo com Lussac $(1996$, p. 37) a capoeira desenvolve a potencialidade cognitiva em conjunto com as habilidades motoras, pois,

Da parte cognitiva, podemos ver a busca da harmonia do corpo com a mente, através do aprendizado dos instrumentos e de movimentos em que sua percepção se dá, às vezes, de última hora, atiçando a criatividade e a improvisação com o corpo, melhorando a coordenação motora. o aluno toma parte da evolução, funcionamento e limites de seu corpo, descobrindo-o e disciplinando-o.

Assim, o contato direto com as ramificações da capoeira, e, suas possibilidades adaptativas para cada faixa etária aprimoram as condições conjuntas entre corpo e mente. Embora não fosse foco principal do estudo, pode-se observar durante as vivências corporais que algumas participantes apresentavam dificuldade de memorização, no entanto, a musicalidade da capoeira e suas repetições no refrão das músicas estimularam a concentração e memorização das mesmas. Neste sentido, Bechara (1985) e Lussac (1996) atribuem que a criatividade é uma das principais qualidades da capoeira. Sendo fator primordial para o desenvolvimento cognitivo. A maior validade no aprendizado da capoeira reside no desenvolvimento da criatividade, na qual o capoeirista cria, recria e recria-se, com a sequência que é propiciada durante o seu desenrolar.

A partir da matriz analítica pode-se constatar que três idosas destacaram a presença da socialização por meio da prática da capoeira. De fato, se pensarmos a capoeira enquanto manifestação cultural realizada em grupo, logo, conclui-se que essa modalidade possui potencial estimulatório para ampliação da socialização entre praticantes. A esse respeito, Lussac (2009, p. 54-5) postula ser "comum encontrar entre os praticantes de capoeira o sentimento de família por seu grupo e pelos que o integram, tendo o mestre como figura principal, norteadora desse sistema de interação".

Do mesmo modo, a relação estabelecida com o outro, permite dizer que na capoeira o processo sociabilizador está atrelado às diferentes ações transformadoras dos sujeitos, deixando de ser meramente alguém da sociedade para tornar-se um mediador da cultura, pois, a ação divulgadora da capoeira para sua comunidade fortalece a perspectiva de vida do idoso.

Especificamente neste estudo, tornou-se perceptível a ampliação da socialização à medida que foram 
estabelecidos diferentes movimentos corporais dos quais as idosas solicitavam auxilio umas às outras. Pinto (2007) ressalta que as vivências corporais advindas da capoeira são sobre tudo lúdicas, livres e prazerosas, diversificadas e compartilhadas com o outro, exercitando a autonomia dos sujeitos, favorecendo a ampliação do sentido/significado das diferentes práticas corporais.

\section{CONSIDERAÇÕES FINAIS}

Ao fim deste estudo, novas lacunas surgiram, mas, também houve a compreensão da importância de novas leituras acerca da prática da capoeira, bem como o papel do profissional da Educação Física, visto que, a capoeira pode se ampliar constantemente atendendo a múltipla demanda mercadológica. Se em seu contexto histórico a capoeira se inicia como luta de resistência, na atualidade suas ramificações perpassam o conceito reducionista de jogo, esporte, luta, dança. Especificamente nesta abordagem, pode-se dizer que a capoeira se valeu por várias dimensões, hora como atividade física, promovendo as idosas à oportunidade de uma vivência corporal completa, hora como processo socializador, na qual as praticantes se inter-relacionavam para um fim comum.

Por tanto, me valho das descobertas dos diferentes campos de atuação/intervenção que se pode realizar com a capoeira. Pois, a partir da sistematização de ensino da capoeira para idosos, podemos constatar que essa modalidade transcende o que se propôs neste estudo. Inicialmente, o que se buscava verificar centrava-se na aceitação da capoeira por um grupo especifico (idosos), cuja intenção voltaram-se as possíveis melhorias que essa prática pudesse atribuir. Todavia, outros aspectos do desenvolvimento humano foram acionados, assim, pode-se atribuir que a capoeira serviu como uma espécie de dispositivo gerador de diferentes melhorias, dentre elas a agilidade, coordenação motora, ritmo, minimização de esquecimento, e possivelmente a ampliação do condicionamento físico.

Nesse sentido, a capoeira para idosos transcende a dualidade luta/jogo, pois, proporciona melhorias nas qualidades físicas de seus praticantes, aumento de alegria, autoconfiança e reconhecimento do contexto histórico da chegada do negro no Brasil. Assim, as discussões direcionadas a prática da capoeira para idosos ainda se encontra com certas limitações, tanto na compreensão conceitual quanto nas ações práticas. Por tanto, conclui-se que a análise da sistematização de ensino da capoeira e o como fazer desta modalidade se faz presente no universo capoeirístico. E essa nova forma de atuar/intervir com a capoeira possibilita adequações para qualquer faixa etária.

\section{REFERÊNCIAS}

ANGHEBEN, V. L. Z. A Ginástica rítmica na corporeidade dos acadêmicos de educação física: relações entre o pensar, falar e agir com o corpo. 2005. 221f. Dissertação (Mestrado em Ciências do Movimento Humano) - Universidade do Rio Grande do Sul: Porto Alegre, 2005.

BARBANTI, V. J. Dicionário de educação física e do esporte. 2. ed. São Paulo: Manole, 2003.

BARDIN, L. Análise de conteúdo. São Paulo: Martins Fontes, 1977.

BECHARA, M. A. Capoeira: um esporte que educa. Revista Artus, Rio de Janeiro, n. 16, p. 30-1, 1985.

BRANDL, C. E. H. A consciência corporal na perspectiva da educação física. Revista do Conselho Federal de Educação Física, v. 26, n. 3, p. 31, 2002. Disponível em: <http://www.confef.org.br/extra/ revistaef/arquivos/2002/N02 MAR\%C3\%870/06 CONSCIENCIA_CORPORAL.PDF>. Acessado em: 18 de dezembro de 2016.

BRASIL. Ministério da Saúde. Secretaria de Vigilância em Saúde. Secretaria de Atenção à Saúde. Política Nacional de Promoção da Saúde/Ministério da Saúde, Secretaria de Vigilância em Saúde, Secretaria de Atenção em Saúde. 3. ed. Brasília: Ministério da Saúde, 2010.

BRENNECKE, A.; AMADIO, A. C.; SERRÃO, J. C. Parâmetros dinâmicos de movimentos selecionados da capoeira. Revista Portuguesa de Ciências do Desporto, Porto, v. 5, n. 2, p. 153-9, 2005.

CAVALARI, T. A. Consciência corporal na escola. 2005. 173f. Dissertação (Mestrado em Educação 
Física) - Faculdade de Educação Física, Universidade Estadual de Campinas, Campinas, 2005.

COELHO, M. G. F.; GOBBI, S.; COSTA, R. L. J.; GOBBI, B. T. L. Exercício físico no envelhecimento saudável e patológico: da teoria a prática. Curituba: CRV: 2013.

DUARTE, R. Pesquisa qualitativa: reflexões sobre o trabalho de campo. Cadernos de Pesquisa [online], São Paulo, n. 115, p. 139-54, 2002. Disponível em: <http://www.scielo.br/scielo.php?pid=S0100$15742002000100005 \&$ script=sci_abstract\&tlng=pt>. Acessado em: 13 de julho de 2016.

FRANCHI, B. M. K.; JUNIOR, M. M. R. Atividade física: uma necessidade para a boa saúde na terceira idade. Revista Brasileira em Promoção da Saúde, v. 18, n. 3, p. 152-6, 2005.

GALDINO, L. A. S.; NOGUEIRA, C. J.; CÉSAR, E. P.; FORTES, M. E. P.; PERROUT, J. R.; DANTAS, E. H. M. Comparação entre níveis de força explosiva de membros inferiores antes e após flexionamento passivo. Fitness and Performance Jornal, Rio de Janeiro. v. 4, n. 1, p. 11, p. 11-5, 2005.

LUSSAC, R. M. P. A polivalência de la multifacetada capoeira. Lectures: Educación Física y Deportes, Revista Digital, Buenos Aires, v. 14, n. 142, 2010. Disponível em: <http://www.efdeportes.com/ efd142/a-polivalencia-da-multifacetada-capoeira.htm>. Acessado em: 13 de dezembro de 2016.

LUSSAC, R. M. P. Desenvolvimento psicomotor fundamentado na prática da capoeira e baseado na experiência e vivência de um mestre da capoeiragem graduado em educação física. 2004. 450f. Monografia (Especialização em Psicomotricidade) - Universidade Cândido Mendes, Rio de Janeiro, 2004. Disponível em: <http://www.avm.edu.br/monopdf/7/RICARDO\%20MARTINS\%20PORTO\%20 LUSSAC.pdf>. Acessado em: 22 de maio de 2016.

LUSSAC, R. M. P. Estudo da metodologia do ensino da capoeira. Sprint Magazine, Rio de Janeiro, v. 15, n. 84, p. 36-8, 1996.

LUSSAC, R. M. P. Terceira idade, envelhecimento e capoeira. Revista Brasileira de Ciências do Envelhecimento Humano, Passo Fundo, v. 6, n. 1, p. 50-60, 2009.

MEDINA, J. P. S. A educação física cuida do corpo... e mente: bases para a renovação e transformação da educação física. 9. ed. Campinas: Papirus, 1987.

MILLER, J. C. A escuta do corpo: abordagem da sistematização da técnica Klauss Vianna. 2005. 129f. Dissertação (Mestrado em Artes) - Instituto de Artes, Universidade Estadual de Campinas, Campinas, 2005.

OKUMA, S. S. O idoso e a atividade física: fundamentos e pesquisa. 5. ed. Campinas: Papirus, 2009.

PORTEIA, V. P.; JESUS, L. H. Capoeira pedagógica: olhares sobre a cultura do movimento na educação. Cuiabá: Unemat, 2011.

REIS, A. L. T. Educação física e capoeira: saúde e qualidade de vida. Brasília: Thesaurus, 2001.

SANTOS, S. L. Capoeira uma expressão antropológica da cultura brasileira. Maringá: Programa de Pós-Graduação em Geografia-UEM, 2002.

VERONESE, F.; MORÉ, C. L. O. O. A capoeira como instrumento e recurso terapêutico para pessoas com sofrimento psíquico. Revista Eletrônica de Extensão, Florianópolis, v. 6, n. 8, p. 50-63, 2009. Disponível em <https://periodicos.ufsc.br/index.php/extensio/article/view/18070221.2009v6n8p50>. Acessado em: 09 de janeiro de 2018.

Autor correspondente: Silvana Santos

E-mail: silsantos2611@outlook.com

Recebido: 22 de dezembro de 2017. Aceito: 23 de abril de 2018. 